\title{
HUBUNGAN PERILAKU IBU DIRUMAH DENGAN KEBERSIHAN GIGI DAN MULUT PADA MURID KELAS V SEKOLAH DASAR NEGERI DI KOTA BANDA ACEH
}

\author{
Nia kurniawati ${ }^{1}$, Herry $\operatorname{Imran}^{1}$ \\ ${ }^{1}$ Jurusan Keperawatan Gigi Poltekkes Kemenkes Aceh, Jln. Soekarno Hatta Desa Lagang Kabupaten Aceh Besar \\ *Corresponding Author : niakurniawati679@gmail.com
}

\begin{abstract}
Abstrak
Perilaku manusia adalah semua kegiatan atau aktifitas manusia, baik yang dapat diamati secara langsung ataupun secara tidak laangsung. Sikap dan perilaku ibu sangat mempengaruhi anak dalam menjaga kebersihan gigi dan mulut karena ibu merupakan orang terdekat dengan anak. Dalam pemeliharaan kesehatan gigi memberi pengaruh yang sangat signifikasi terhadap sikap dan perilaku anak. Tujuan penelitian ini adalah mengetahui hubungan pengetahuan, sikap dan tindakan ibu dirumah dengan kebersihan gigi dan mulut pada murid kelas V SD Negeri Kota Banda Aceh. Penelitian ini bersifat analitik, yang telah dilaksanakan pada bulan Agustus 2018 dengan melakukan pemeriksaan OHI-S terhadap murid dan melakukan wawancara terhadap ibu murid. Sampel dalam penelitian ini menggunakan teknik total sampling yaitu 60 murid dan 60 ibu murid. Analisis data menggunakan uji Chi-Square $(\alpha=0,05)$. Hasil penelitian menunjukkan bahwa responden dengan pengetahuan tertinggi pada kriteria baik yaitu sebanyak 36 orang (74\%), sikap tertinggi pada kriteria baik yaitu sebanyak 38 orang (73\%), dan tindakan tertinggi pada kriteria baik sebanyak 35 orang (69\%). Berdasarkan hasil uji statistik bahwa ada hubungan pengetahuan $(\mathrm{p}=0,02)$, ada hubungan sikap $(\mathrm{p}=0,01)$ dan tidak ada hubungan tindakan $(\mathrm{p}=$ 0,72 ) dengan status kebersihan gigi dan mulut. Disarankan kepada ibu agar dapat memotivasi anak dalam menjaga kebersihan gigi dan mulut, seperti memberikan contoh menyikat gigi sehari dua kali yaitu sesudah sarapan dan sebelum tidur.
\end{abstract}

Kata Kunci : pengetahuan, sikap, tindakan-dan-kebersihan-gigi-dan-mulut 


\title{
Relationship of Mother's Behavior Home with Dental And Mouth Cleaning at Vocational School of State School In Banda Aceh
}

\begin{abstract}
Human behavior is all human activities or activities, whether they can be observed directly or indirectly. The attitude and behavior of the mother greatly affects the child in maintaining dental and oral hygiene because the mother is the closest person to the child. In maintaining dental health gives a very significant influence on the attitudes and behavior of children. The purpose of this study was to determine the relationship of knowledge, attitudes and actions of mothers at home with dental and oral hygiene in class V students of SDN Banda Aceh. This research is analytical, which was held in August 2018 by conducting an OHI-S examination of students and conducting interviews with mothers of students. The sample in this study used a total sampling technique, namely 60 students and 60 mothers. Data analysis using Chi-Square test $(\alpha=0.05)$. The results showed that respondents with the highest knowledge of good criteria were as many as 36 people (74\%), the highest attitudes on good criteria as many as 38 people $(73 \%)$, and the highest actions on good criteria were 35 people $(69 \%)$. Based on the results of statistical tests that there is a relationship of knowledge $(p=0.02)$, there is an attitude relationship $(p=0.01)$ and there is no relationship of action $(\mathrm{p}=0.72)$ with dental and oral hygiene status. It is recommended to mothers to be able to motivate children to maintain clean teeth and mouth, such as giving examples of brushing teeth twice a day, namely after breakfast and before going to bed.
\end{abstract}

Keywords: knowledge, attitudes, actions-and-dental-and-oral-hygiene 


\section{PENDAHULUAN}

Undang-Undang RI N0.36 Tahun 2009 pasal 46 dan 47 menyatakan bahwa untuk mewujudkan derajat kesehatan yang setinggi-tingginya bagi masyarakat, diselenggarakan upaya kesehatan yang terpadu dan menyeluruh dalam bentuk upaya kesehatan perseorangan dan upaya kesehatan masyarakat. Upaya kesehatan diselenggarakan dalam bentuk kegiatan dengan pendekatan promotif, preventive, kuratif, dan rehabilitative yang dilaksanakan secara terpadu, menyeluruh, dan berkesinabungan ${ }^{4}$

Pembangunan di bidang kesehatan bertujuan untuk meningkatkan derajat kesehatan masyarakat agar tingkat kesehatan masyarakat menjadi lebih baik. Pembangunan di bidang kesehatan gigi merupakan bagian integral pembangunan kesehatan nasional. Artinya, dalam melaksanakan pembangunan kesehatan, pembangunan di bidang kesehatan gigi tidak boleh di tinggalkan, demikian juga sebaliknya. Bila ingin melaksanakan pembangunan di bidang kesehatan gigi, tidak boleh dilupakan kerangka yang lebih luas, yaitu pembangunan di bidang kesehatan umumnya ${ }^{20}$

Pendidikan kesehatan gigi adalah suatu penerapan atau aplikasi konsep pendidikan dan konsep sehat. Konsep sehat adalah seseorang dalam keadaan sempurna baik fisik, mental, dan sosialnya serta bebas dari penyakit, cacat, dan kelemahannya. Seperti halnya pendidikan kesehatan, konsep pendidikan kesehatan gigi pun merupakan penerapan dari konsep pendidikan dan konsep sehat. Bertitik tolak dari kedua konsep tersebut, maka pendidikan kesehatan gigi adalah suatu proses belajar yang di tujukan kepada individu dan kelompok masyarakat untuk mencapai derajat kesehatan gigi yang setinggi-tingginya ${ }^{6}$

Perilaku adalah suatu kegiatan atau aktivitas organisme yang bersangkutan. Perilaku manusia pada hakekatnya adalah suatu aktivitas dari pada manusia itu sendiri. Perilaku adalah semua kegiatan atau aktifitas manusia, baik yang dapat diamati secara langsung ataupun secara tidak langsung 11

Pendidikan kesehatan gigi harus diperkenalkan sedini mungkin kepada anak agar mereka dapat mengetahui cara memelihara kesehatan gigi dan mulut secara baik dan benar.Ibu sangat berpengaruh dalam pemeliharaan kesehatan dan kebersihan gigi dan mulut anak karena anak masih bergantung pada ibu. Sikap dan perilaku ibu sangat menpengaruhi anak dalam menjaga kebersihan gigi dan mulut.Ibu harus mampu memberikan contoh yang baik dalam menjaga kesehatan gigi dan mulut. Karena ibu merupakan orang terdekat dengan anak dalam 
pemeliharaan kesehatan gigi memberikan pengaruh yang sangat signifikasi terhadap sikap dan perilaku anak $^{16}$

Pemeliharaan kebersihan gigi dan mulut pada anak usia sekolah merupakan hal yang sangat penting mengingat pada saat inilah seorang anak dalam masa tumbuh kembangnya,oleh karena itu peran ibu dalam pemeliharaan kebersihan gigi dan mulut anak menjadi pendidikan yang paling dasar dalam membentuk kepribadian anak agar selalu menjaga kebersihan gigi dan mulutnya sendiri.Sehingga pada saat anak memasuki usia dewasa,seorang anak telah siap dengan sesuatu hal yang baru yang akan dijalaninya tanpa terganggu oleh permasalahan kesehatan gigi yang dapat mempengaruhi kesehatan secara umum dan segala proses pendidikan yang dijalaninya $^{9}$

Berdasarkan hasil riset kesehatan dasar (RISKESDAS, 2013) dimana 25,2\% anak Indonesia kelompok usia (10-14 tahun) mempunyai masalah gigi dan mulut dan pada Masyarakat Banda Aceh sebanyak 30,5\% mempunyai masalah gigi dan mulut. Berdasarkan data yang diperoleh Riset Kesehatan Dasar (Riskesdas) 2013 yang menggambarkan sebagian besar penduduk umur 10 tahun keatas 95,7\% mempunyai kebiasaan menggosok gigi setiap hari. Untuk mendapatkan hasil yang optimal, menggosok gigi yang benar adalah menggosok gigi setiap hari pada waktu pagi hari sesudah makan dan malan sebelum tidur. Didapatkan pada umumnya masyarakat yang menggosok gigi setiap hari pada waktu mandi pagi atau sore 78,1\%. Masyarakat yang menggosok gigi setiap hari sesudah makan pagi hanya 3,2\% dan sebelum tidur malam 22,4\%. Persentase penduduk yang benar menggosok gigi yaitu 1,7\%, sedangkan persentase penduduk yang berperilaku tidak benar menggosok gigi sangat besar yaitu 98,3\%. Diprovinsi NAD sebagian besar penduduk umur 10 tahun keatas 89,9\% memepunyai kebiasaan menggosok gigi setiap hari, 71,7\% masyarakat yang menggosok gigi setiap hari pada waktu mandi pagi atau sore, hanya 4,1\% masyarakat yang menggosok gigi setiap hari sesudah makan pagi dan 29,7\% masyarakat menggosok gigi sebelum tidur malam. Persentase penduduk yang benar menggosok gigi yaitu 2,2\%, sedangkan persentase penduduk yang berperilaku tidak benar menggosok gigi sangat besar yaitu 95,1\%. Derektorat Kesehatan Gigi Departemen Kesehatan (2000) telah menetapkan sasaran jangka panjang program Kesehatan Gigi dan mulut, yakni suatu derajat kesehatan gigi dan mulut yang optimal dengan ukuran kebersihan mulut dilingkungan anak Sekolah Dasar dengan angka Oral Hygiene Index Simplified (OHIS) berkisar nilai 0,6-1,2. 
Berdasarkan latar belakang diatas, maka tujuan penelitian adalah untuk mengetahui hubungan pengetahuan Ibu, sikap ibu dan tindakan ibu dirumah dengan kebersihan gigi dan mulut pada murid kelas V SD Negeri Kota Bata Banda Aceh.

\section{METODE PENELITIAN}

Penelitian ini bersifat analitik,yaitu untuk mencari Hubungan Perilaku Ibu dirumah Dengan Kebersihan Gigi Dan Mulut Pada Murid Kelas V SD Negeri Kota Banda Aceh. Penelitian ini dilaksanakan di SD Negeri Kota Banda Aceh. Penelitian ini akan dilaksanakan pada bulan Mei sampai Agustus 2018. Populasi dalam penelitian ini adalah seluruh murid V SD Negeri Kota Banda Aceh yang berjumlah 60 murid dan 60 ibu murid. Metode pengambilan sampel pada penelitian ini menggunakan teknik total sampling, dimana seluruh murid Kelas $\mathrm{V}$ SD Negeri Kota Banda Aceh yang berjumlah 60 murid dan 60 ibu murid. Instrumen yang di gunakan dalam penelitian ini adalah kuesioner, kartu status pasien, diagnosa set.

\section{HASIL PENELITIAN}

Penelitian telah dilakukan pada bulan Agustus 2018 di SD Negeri Kota Banda Aceh, sampel dalam penelitian ini berjumhlah $60 \mathrm{ibu}$ dan 60 anak, dimana hasil pengolahan data diperoleh dari wawancara langsung yang dilakukan oleh peneliti terhadap ibu murid dan melakukan pemeriksaan langsung pada murid. Hasil penelitian diketahui bahwa responden dengan jenis kelamin laki-laki sebanyak $50 \%$ dan jenis kelamin perempuan sebanyak $50 \%$. Tingkat pendidikan ibu yang paling banyak yaitu pendidikan SMA sebanyak 35\%.

\section{A. Perilaku Ibu Terhadap Kebersihan Gigi dan Mulut Anak}

\section{a. Tabel Hubungan Pengetahuan Ibu Terhadap kebersihan gigi dan Mulut Pada Murid}




\section{Tabel 1}

Distribusi Frekuensi Hubungan Pengetahuan Ibu Terhadap Kebersihan Gigi Dan Mulut Pada Murid kelas V SD Negeri Kota Banda Aceh

\begin{tabular}{|c|c|c|c|c|c|c|c|c|c|c|c|c|}
\hline \multirow{3}{*}{ No } & \multirow{3}{*}{$\begin{array}{c}\text { Pengetahuan ibu terhadap Kebersihan } \\
\text { Gigi dan mulut }\end{array}$} & \multicolumn{6}{|c|}{ OHI-S } & \multirow{3}{*}{ Total } & \multirow{3}{*}{$\%$} & \multirow{3}{*}{$\alpha$} & \multirow{3}{*}{ df } & \multirow{3}{*}{$\mathbf{P}$} \\
\hline & & \multicolumn{2}{|c|}{ Baik } & \multicolumn{2}{|c|}{ Sedang } & \multicolumn{2}{|c|}{ Buruk } & & & & & \\
\hline & & $\mathrm{F}$ & $\%$ & $\mathrm{~F}$ & $\%$ & $\mathrm{~F}$ & $\%$ & & & & & \\
\hline 1 & Baik $\geq 50 \%$ & 7 & 14 & 36 & 74 & 6 & 12 & 49 & 100 & & & \\
\hline 2 & Kurang baik $<50 \%$ & 2 & 18 & 4 & 36 & 5 & 46 & 11 & 100 & 0,05 & 2 & 0,02 \\
\hline & Total & 9 & 15 & 40 & 67 & 11 & 18 & 60 & 100 & & & \\
\hline
\end{tabular}

Berdasarkan tabel 1 diatas dari 60 orang yang memiliki pengetahuan baik dengan status kebersihan gigi dan mulut pada kriteria sedang yaitu sebanyak 74\%, dan yang memiliki pengetahuan kurang baik dengan status kebersihan gigi dan mulut pada kriteria buruk yaitu 46\%. Berdasarkan hasil uji statistik bahwa ada hubungan antara pengetahuan ibu dengan status kebersihan gigi dan mulut ( $\mathrm{p}=0,02)$.

\section{b. Tabel Hubungan Sikap Ibu Terhadap Kebersihan Gigi dan Mulut Murid}

Tabel 2

\section{Distribusi Frekuensi Hubungan Sikap Ibu Terhadap Kebersihan Gigi Dan Mulut Pada Murid kelas V SD Negeri Kota Banda Aceh}

\begin{tabular}{|c|c|c|c|c|c|c|c|c|c|c|c|c|}
\hline \multirow{3}{*}{ No } & \multirow{3}{*}{$\begin{array}{c}\text { Sikap Ibu Terhadap } \\
\text { Kebersihan gigi dan } \\
\text { mulut }\end{array}$} & \multicolumn{6}{|c|}{ OHI-S } & \multirow{3}{*}{ Total } & \multirow{3}{*}{$\%$} & \multirow{3}{*}{$\alpha$} & \multirow{3}{*}{ df } & \multirow{3}{*}{$\mathbf{p}$} \\
\hline & & \multicolumn{2}{|c|}{ Baik } & \multicolumn{2}{|c|}{ Sedang } & \multicolumn{2}{|c|}{ Buruk } & & & & & \\
\hline & & $\mathbf{F}$ & $\%$ & $\mathbf{F}$ & $\%$ & $\mathbf{F}$ & $\%$ & & & & & \\
\hline 1 & Baik $\geq 50 \%$ & 7 & 13 & 38 & 73 & 7 & 14 & 52 & 100 & & & \\
\hline 2 & Kurang baik $<50 \%$ & 2 & 25 & 2 & 25 & 4 & 50 & 8 & 100 & 0,05 & 2 & 0,01 \\
\hline & Total & 9 & 15 & 40 & 67 & 11 & 18 & 60 & 100 & & & \\
\hline
\end{tabular}

Berdasarkan tabel 2 diatas dari 60 orang yang memiliki sikap baik dengan status kebersihan gigi dan mulut pada kriteria sedang yaitu sebanyak $73 \%$, dan yang memiliki sikap kurang baik dengan status kebersihan gigi dan mulut pada kriteria buruk yaitu $50 \%$. Berdasarkan hasil uji statistik bahwa ada hubungan antara sikap ibu dengan status kebersihan gigi dan mulut $(\mathrm{p}=0,01)$. 


\section{c. Tabel Hubungan Tindakan Ibu Terhadap Kebersihan Gigi dan Mulut Murid}

Tabel 3

\section{Distribusi Frekuensi Hubungan Tindakan Ibu Terhadap Kebersihan Gigi Dan Mulut Pada Murid kelas V SD Negeri Kota Banda Aceh}

\begin{tabular}{|c|c|c|c|c|c|c|c|c|c|c|c|c|}
\hline \multirow{3}{*}{ No } & \multirow{3}{*}{$\begin{array}{c}\text { Tindakan Ibu } \\
\text { Terhadap } \\
\text { Kebersihan gigi dan } \\
\text { mulut }\end{array}$} & \multicolumn{6}{|c|}{ OHI-S } & \multirow{3}{*}{ Total } & \multirow{3}{*}{$\%$} & \multirow{3}{*}{$\alpha$} & \multirow{3}{*}{ df } & \multirow{3}{*}{$\mathbf{P}$} \\
\hline & & \multicolumn{2}{|c|}{ Baik } & \multicolumn{2}{|c|}{ Sedang } & \multicolumn{2}{|c|}{ Buruk } & & & & & \\
\hline & & $\mathbf{F}$ & $\%$ & $\mathbf{F}$ & $\%$ & $\mathbf{F}$ & $\%$ & & & & & \\
\hline 1 & Baik $\geq 50 \%$ & 7 & 14 & 35 & 69 & 9 & 17 & 51 & 100 & & & \\
\hline 2 & Kurang baik $<50 \%$ & 2 & 22 & 5 & 56 & 2 & 22 & 9 & 100 & 0,05 & 2 & 0,72 \\
\hline & Total & 9 & 15 & 40 & 67 & 11 & 18 & 60 & 100 & & & \\
\hline
\end{tabular}

Berdasarkan table 3 diatas dari 60 orang yang memiliki tindakan baik dengan status kebersihan gigi dan mulut pada kriteria sedang yaitu sebanyak 69\%, dan yang memiliki tindakan kurang baik dengan status kebersihan gigi dan mulut pada kriteria sedang yaitu 56\%. Berdasarkan hasil uji statistik bahwa tidak ada hubungan antara tindakan ibu dengan status kebersihan gigi dan mulut $(\mathrm{p}=0,72)$.

d. Status kebersihan gigi dan mulut

Tabel 4

Distribusi Frekuensi Kebersihan Gigi dan Mulut Pada Murid kelas V SD Negeri Kota Banda Aceh

\begin{tabular}{|c|c|c|c|}
\hline No & Kriteria OHIS & Frekuensi & Persentase \\
\hline 1 & Baik & 9 & 15 \\
\hline 2 & Sedang & 40 & 67 \\
\hline 3 & Buruk & 11 & 18 \\
\hline & Jumlah & 60 & 100 \\
\hline
\end{tabular}

Berdasarkan tabel 4 diatas, dari 60 responden yang diperiksa terlihat bahwa yang mempunyai kebersihan gigi dan mulut yang terbanyak pada kategori sedang yaitu sebanyak 40 orang $(67 \%)$ dan yang terendah pada kategori baik yaitu sebanyak 9 orang $(15 \%)$. 


\section{PEMBAHASAN}

Berdasarkan hasil penelitian yang dilakukan pada bulan Agustus 2018, Pada 60 Murid kelas V SD Negeri Kota Banda Aceh dan 60 ibu murid sebagai responden, yaitu 30 murid dengan jenis kelamin laki-laki dan 30 murid dengan jenis kelamin perempuan, didapatkan status kebersihan gigi dan mulut anak dengan kriteria OHI-S baik 9 orang (15\%), kriteria OHI-S sedang 40 orang $(66,7 \%)$ dan dengan kriteria OHI-S buruk 11 orang $(18,3 \%)$.

Peneliti berasumsi hal ini disebabkan karena walaupun ibu telah mengetahui segala sesuatu menyangkut kebersihan gigi dan mulut anak, telah bertindak untuk merawat gigi anak, tetapi ibu tidak bisa mengawasi anak pada saat anak disekolah dan bermain dilingkungan luar rumah sehingga pada saat itulah anak berperilaku sendiri. Disekolah mereka jajan makanan yang dapat merusak gigi dan setelah makan mereka malas berkumur-kumur,

oleh sebab itu terbentuklah Oral Hygiene yang buruk pada anak. Kebersihan mulut merupakan suatu kondisi atau keadaan terbebasnya gigi geligi dari plak dan kalkulus, keduanya selalu terbentuk pada gigi dan meluas ke seluruh permukaan gigi. Hal ini disebabkan karena rongga mulut bersifat basah, lembab dan gelap, dengan kata lain lingkungan yang menyebabkan kuman berkembang biak $^{2}$

\section{Hubungan Pengetahuan Ibu Terhadap Kebersihan Gigi dan Mulut Anak.}

Berdasarkan tabel 1 diatas dari 60 orang yang memiliki pengetahuan baik dengan status kebersihan gigi dan mulut pada kriteria sedang yaitu sebanyak 74\%, dan yang memiliki pengetahuan kurang baik dengan status kebersihan gigi dan mulut pada kriteria buruk yaitu 46\%. Berdasarkan hasil uji statistik bahwa ada hubungan antara pengetahuan ibu dengan status kebersihan gigi dan mulut $(\mathrm{p}=0,02)$.

Penulis berasumsi bahwa tingkat pengetahuan ibu terhadap kebersihan gigi dan mulut sudah berkategori tinggi, tetapi memiliki status kebersihan gigi dan mulut anak dengan kriteria sedang. Peneliti berasumsi bahwa mereka bisa memperoleh pengetahuan tentang kebersihan gigi dan mulut dari berbagai sumber yang diterimanya misalnya penyuluhan tentang kesehatan gigi dan mulut yang dilakukan oleh tenaga kesehatan dari puskesmas setempat serta diperoleh dari media audio dan visual, sehingga terbentuk pengetahuan tentang kebersihan gigi dan mulut. 
Sejalan dengan teori yang dikemukakan, pengetahuan ibu sangat penting dalam mendasari terbentuknya perilaku yang mendukung atau tidak mendukung kebersihan gigi dan mulut anak. Pengetahuan tersebut dapat diperoleh secara alami maupun secara terencana yaitu melalui proses pendidikan, ibu dengan pengetahuan rendah mengenai kesehatan gigi dan mulut merupakan faktor predisposisi dari perilaku yang tidak mendukung kesehatan gigi dan mulut anak ${ }^{17}$. Proses pelaksanaan instruksi kebersihan gigi dan mulut membutuhkan serangkaian proses yang dapat dimulai dengan mengajarkan ibu atau pengasuh. Teknik penerapan upaya ini sesuai dengan perkembangan kemampuan motorik dan kecerdasan anak. Berbagai sikap dan perilaku anak akan muncul pada saat dimulainya proses ini. Namun demikian anak akan mudah menyesuaikan apabila telah terjalin komunikasi yang interaktif antara anak dengan ibu atau pengasuh. pengetahuan yang baik apabila tidak disertai oleh kesadaran, sikap dan tindakan maka tidak akan bersifat lama ${ }^{11}$

\section{Hubungan Sikap ibu terhadap kebersihan gigi dan mulut anak}

Berdasarkan tabel 2 diatas dari 60 orang yang memiliki sikap baik dengan status kebersihan gigi dan mulut pada kriteria sedang yaitu sebanyak 73\%, dan yang memiliki sikap kurang baik dengan status kebersihan gigi dan mulut pada kriteria buruk yaitu 50\%. Berdasarkan hasil uji statistik bahwa ada hubungan antara sikap ibu dengan status kebersihan gigi dan mulut $(\mathrm{p}=$ $0,01)$.

Hal ini menunjukkan bahwa sikap ibu terhadap kebersihan gigi dan mulut anak sudah berkategori tinggi, tetapi memiliki status kebersihan gigi dan mulut anak yang sedang. Peneliti berasumsibahwa sikap sebagai kecendrungan untuk merespon dan ada faktor yang mempengaruhi sikap ibu, sehingga walaupun sikap ibu baik, belum tentu kebersihan gigi dan mulut anak juga baik, sikap merupakan ancang-ancang untuk bertindak jadi pada saat ibu telah tau dan setuju suatu pernyataan tentang kebersihan gigi dan mulut, ada faktor lain yang menyebabkan ibu gagal dalam melakukan tindakan, sebagai mana kita ketahui seorang ibu merupakan orang yang mengurus rumah tangga, sehingga pada saat mengurus kesibukannya yang lain ibu akan lupa menyikapi masalah tentang kebersihan gigi dan mulut anaknya.Hal ini didukung oleh sebuah teori yaitu sikap merupakan suatu kesimpulan atau kesediaan untuk bertindak dan bukan motif tertentu, sikap belum merupakan suatu tindakan atau aktifitas, akan tetapi predisposisi tindakan dan prilaku ${ }^{11}$ 


\section{Hubungan Tindakan Ibu terhadap kebersihan gigi dan mulut anak}

Berdasarkan tabel 3 diatas dari 60 orang yang memiliki tindakan baik dengan status kebersihan gigi dan mulut pada kriteria sedang yaitu sebanyak 69\%, dan yang memiliki tindakan kurang baik dengan status kebersihan gigi dan mulut pada kriteria sedang yaitu 56\%. Berdasarkan hasil uji statistik bahwa tidak ada hubungan antara tindakan ibu dengan status kebersihan gigi dan mulut $(\mathrm{p}=0,72)$.

hal ini menunjukkan bahwa tindakan ibu terhadap kebersihan gigi dan mulut anak sudah berkategori tinggi, tetapi memiliki status kebersihan gigi dan mulut anak yang sedang. Peneliti berasumsi bahwa tindakan merupakan respon yang ditimbulkan dari hasil pengetahuan dan sikap. Ibu telah bertindak dengan baik terhadap anak pada saat anak masih dalam pengawasannya, usia anak Sekolah Dasar merupakan usia yang sangat rentan terhadap timbulnya permasalahan gigi dan mulut, karena pada saat anak berada di lingkungan sekolah anak akan bertindak sendiri dan akan lupa dan mengabaikan apa yang telah diiajarkan ibunya pada saat dirumah. Dalam hal ini di pengaruhi oleh praktek terpimpin, yaitu apabila suatu objek atau seseorang telah melakukan sesuatu tetapi masih tergantung pada tuntunan atau panduan. Misalnya seorang anak menggosok gigi namun masih selalu diingatkan oleh ibunya, adalah masih disebut praktik atau tindakan terpimpin, sehingga pada saat anak diluar pengawasan ibu disinilah terjadi permasalahan tentang kebersihan gigi dan mulut anak ${ }^{12}$

\section{KESIMPULAN DAN SARAN}

Setelah dilakukan penelitian, dapat di simpulkan sebagai berikut:

1. Ada hubungan antara pengetahuan ibu dengan status kebersihan gigi dan mulut pada murid kelas V SD Negeri Kota Banda Aceh $(\mathrm{p}=0,02)$

2. Ada hubungan antara sikap ibu dengan status kebersihan gigi dan mulut pada murid kelas V SD Negeri Kota Banda Aceh ( $\mathrm{p}=0,01)$

3. Tidak ada hubungan antara tindakan ibu dengan status kebersihan gigi dan mulut pada murid kelas V SD Negeri Kota Banda Aceh ( $p=0,72$ )

4. Status kebersihan gigi dan mulut pada murid kelas V SD Negeri Kota Banda Aceh rata rata berkategori sedang $(60 \%)$ 
Berdasarkan kesimpulan diatas maka dapat direkomendasikan :

1. Disarankan kepada ibu agar dapat memotivasi anak dalam menjaga kebersihan gigi dan mulut anaknya, seperti memberikan contoh menyikat gigi sehari dua kali yaitu sesudah sarapan dan sebelum tidur.

2. Diharapkan kepada sekolah agar meningkatkan dan membuat program penyuluhan tentang pemeliharaan kesehatan gigi dan mulut kepada pihak instansi kesehatan atau Puskesmas Wilayah kerja setempat dan untuk mendukung serta meningkatkan program UKGS.

3. Diharapkan kepada puskesmas memiliki jadwal rutin untuk pengecekkan kesehatan gigi dan mulut siswa setiap tiga bulan sekali atau enam bulan sekali.

4. Diharapkan peneliti lainnya untuk dapat melakukan penelitian lebih lanjut dengan cakupan yang lebih bergam, sehingga hasilnya dapat digunakan secara umum untuk perkembangan kesehatan gigi dan mulut.

\section{UCAPAN TERIMA KASIH}

Penulis mengucapkan terima kasih yang sebesar-besarnya kepada pihak PPSDM yang telah memfasilitasi dalam penyusunan artikel ilmiah, Dinas Pendidikan Kota Banda Aceh, murid dan ibunya yang telah membantu dalam pengumpulan data serta semua pihak yang telah membantu terlaksananya penelitian ini.

\section{REFERENSI}

1. Budiharto, 2009. Pengantar Ilmu Perilaku Kesehatan Dan Pendidikan Kesehatan Gigi. EGC. Jakarta.

2. Be Kien Nio, 1995, Preventive Dentistry. Yayasan Kesehatan Gigi Indonesia. Bandung

3. Depkes R.I, 2008. Riset Kesehatan Dasar (RISKESDAS) Laporan Nasional 2013. Jakarta

4. _ 2009. Undang-Undang R.I. No. 36 Tentang Kesehatan. Jakarta.

$5 . \quad$, 2000.Cermin Dunia Kedokteran_Kegiatan Penelitian Dilingkungan Derektorat Kesehatan Gigi Departemen Kesehatan. Dierentorat kesehatan Gigi, Jakarta.

6. Herijulianti, E, Indriani, T.S dan Artini, S. 2002. Pendidikan Kesehatan Gigi, EGC. Jakarta.

7. http://idafarida73.blogspot.com/2012/09/cara-mengukur-kebersihan-mulut-ohi-s.html

8. Machfoed. I, 2006. Menjaga Kesehatan Gigi Dan Mulut Anak-anak Dan Ibu Hamil, Fitramaya, yogyakarta.

9. Maulani. C, Jubilee enterprise, 2005. Kiat Merawat Gigi Anak, PT Elex Media Komputindo, Jakarta 
10. Muhariani, I. 2009, Laporan akhir Kepaniteraan Klinik Bagian Ilmu Kedokteran gigi Pencegahan dan Kesehatan Masyarakat.

11. Notoadmodjo, S, 2003. Pendidikan dan Perilaku Kesehatan, Jakarta

12. , 2005. Promosi Kesehatan.Rineka Cipta. Jakarta.

13. Purwanto, N, 2006, http://www.Aryesnovianti.com/2010/12/pengertian-orang-tuamenurut-kunaryo.html

14. Pratiwi, D, 2009. Perawatan Praktis Sehari-hari. Kompas Media Nusantara. Jakarta.

15. , 2007. Gigi Sehat. PT. Kompas Media

16. PDGI, Online, 2009. Inisiatif Kesehatan Gigi dan Mulut sebagai Upaya Dukungan Terhadap Paradigma Sehat. http:/pdgi-online.com

17. Riyanti, E. 2005. Pengenalan dan Perawatan Gigi Sejak Dini. Seminar Sehari KesehatanPsikologi Anak. Jakarta

18. Ramadhan, A, G. 2010.Serba Serbi Kesehatan Gigi dan Mulut. Bukune. Jakarta

19. Smet, B. 1994. Psikologi Kesehatan.PT Grasindo, Indonesia

20. Suwelo, I, S., 1992. Karies Gigi pada Anak dengan Pelbagai Faktor Etiologi Buku Kedokteran EGCJakarta. 